\title{
SEBARAN KONDISI EKOSISTEM HUTAN MANGROVE DI KAWASAN TELUK JAILOLO KABUPATEN HALMAHERA BARAT PROVINSI MALUKU UTARA
}

\author{
Irmalita Tahir, Rustam Effendi Paembonan, Zulhan A Harahap, \\ Nebuchadnezzar Akbar, Eko Setyabudi Wibowo \\ Program Studi IImu Kelautan Universitas Khairun \\ Email : nezzarnebuchad@yahoo.co.id
}

Received August 2017, Accepted September 2017

\begin{abstract}
ABSTRAK
Ekosistem mangrove merupakan salah satu ekosistem utama di wilayah pesisir yang sangat produktif namun sangat rentan terhadap perubahan lingkungan. Pengelolaan ekosistem mengrove harus memperhatikan keterpaduan secara ekologis, ekonomis dan sosial-budaya masyarakat agar pengelolaan secara optimal dan lestari tercapai. Potensi sumber daya ekosistem mangrove di Kawasan Teluk Jailolo cukup besar tetapi kondisi hutan mangrove belum terdata optimal. Tujuan dari penelitian ini untuk mengetahui sebaran kondisi ekosistem hutan mangrove di kawasan Teluk Jailolo, dengan harapan agar pemanfaatan potensi ekosistem mangrove dapat meningkatkan kesejahteraan masyarakat. Metode yang digunakan dengan pendekatan teknologi penginderaan jauh dalam memperoleh data dan informasi spasial tentang kondisi ekosistem mangrove dan pengukuran langsung (survey lapangan) untuk memperoleh data sebaran dan kondisi ekosistem mangrove di kawasan pesisir Teluk Jailolo. Berdasarkan hasil analisis data Citra Alos Avnir-2 bahwa luas mangrove yang terdapat di Teluk Jailolo adalah 393.77 ha, sebagian besar menyebar disekitar garis pantai bagian Timur Teluk Jailolo, dengan kategori tingkat kerapatan sangat jarang hingga lebat. Berdasarkan analisis NDVI diketahui bahwa luas mangrove untuk kategori sangat jarang 20.18 ha, jarang 91.97 ha, sedang 157.83 ha, dan lebat 123.79 ha
\end{abstract}

Kata kunci : Citra Alos Avnir-2, Ekosistem Mangrove, Teluk Jailolo.

\section{ABSTRACT}

Mangrove swamp is one of the productive and essential part in the coastal area. However, it is high risk of the environmental pressure. Thus, the management aspect should be concerned in term of the integrality among ecology, economic, and socio-culture of the community so that optimality of the renewable management can be realized. Despite of large potential of this ecosystem resource, it is lack of the data concerning the ecological 
condition. The aims of the research are to determine the distribution of mangrove ecosystem so that the exploitation of this resource may increase the life quality of the coastal community. The methodology using in this work is the GIS tools to obtain the data and spatial information on mangrove ecosystem condition along the ground survey to produce the data related to the distribution of mangrove species in this site. The results of this investigation using Avnir-2 Alos image data, we found that mangrove existed in Jailolo Bay was 393.77 ha. Most of this mangrove disseminated around at the eastern of coastal line in the area of Jailolo Bay. This part was chategorized as low density to the highest one. According to the NDVI analysis it is clearly that mangrove area was classified as the lowest density of 20.18 ha, low density of 91.97 ha, middle of 157.83 ha and high density of 123.79 ha.

Keywords : Citra Alos Avnir-2, Jailolo Bay, Mangroves Ecosystem.

\section{PENDAHULUAN}

Hutan mangrove merupakan salah satu ekosistem alamiah penting yang memiliki beragam sumberdaya. Secara fisik, hutan mengrove menjadi daerah pelindung daratan dari pengaruh abrasi/erosi ombak. Secara kimia, berfungsi menyaring bahan pencemar (polutan) terutama bahan-bahan organik dan sebagai sumber energi bagi ketersediaan detritus yang merupakan sumber makanan biota/organisme perairan. Secara biologi, berperan sebagai daerah asuhan, daerah pemijahan dan daerah mencari makan berbagai jenis ikan, udang dan biota lainnya, sedangkan secara estetika hutan mangrove berfungsi sebagai tempat parawisata dan pendidikan (Aziz, 2003). Selain itu, serasah mangrove (berupa daun, ranting dan biomassa lainnya) yang jatuh di perairan menjadi sumber pakan biota perairan dan unsur hara yang sangat menentukan produktivitas perikanan perairan laut di depannya. Hutan mangrove juga merupakan habitat (rumah) bagi berbagai jenis burung, reptilia, mamalia dan jenis-jenis kehidupan lainnya, sehingga hutan mengrove menyediakan keanekaragaman (biodiversity) dan plasma nutfah (genetic pool) yang tinggi serta berfungsi sebagai sistem penunjang kehidupan (Dahuri et al, 2001).

Ekosistem mangrove sebagai salah satu ekosistem utama di wilayah pesisir yang sangat produktif, namun sangat rentan terhadap perubahanperubahan atau pengaruh eksternal. Sebagai ekosistem yang rentan, maka pengelolaan ekosistem mengrove harus memperhatikan keterpaduan secara ekologis, ekonomis dan sosial-budaya masyarakat agar pengelolaan secara optimal dan lestari tercapai. Selain itu, wilayah pesisir merupakan suatu wilayah yang unik secara geologis, ekologis, dan merupakan domain biologis yang sangat penting dari berbagi kehidupan di darat dan di perairan, termasuk manusia. Sebagai negara kepulauan, sekitar $65 \%$ penduduk bermukim di wilayah pesisir dan tingkat ketergantungannya terhadap sumberdaya pesisir dan jasa lingkungan 
sangat tinggi. Sehingga tekanan dari proses kegiatan manusia yang tidak terkendali merupakan ancaman bagi sumberdaya alam di wilayah tersebut.

Kawasan ekosistem mengrove di sepanjang wilayah pesisir Teluk Jailolo sudah mulai dimanfaatkan oleh masyarakat namun peranan ekosistem mangrove dalam peningkatan kesejahteraan masyarakat di kawasan tersebut belum memberikan dampak positif yang signifikan. Potensi ekonomis ekosistem mangove dari sektor perikanan seperti berbagai jenis biota laut (ikan, udang dan kepiting) merupakan sumberdaya yang sangat menjanjikan jika dilakukan pengelolaan dan pemanfaatan dengan baik. Potensi lainnya yang belum dimanfaatkan adalah potensi ekowisata, hal ini sangat terkait dengan adanya agenda Festival Teluk Jailolo yang berskala nasional dan diselenggrakan setiap tahunnya.

Berdasarkan studi referensi data dan informasi tentang ekosistem mangrove di Teluk Jailolo masih relatif terbatas. Hal ini disebabkan karena masih rendahnya kajian dan penelitian tentang ekosistem mangrove yang dilakukan di teluk ini. Untuk itu kajian Sebaran Kondisi Ekosistem Hutan Mangrove di Teluk Jailolo perlu dilakukan, agar pengelolaan dan pemanfaatannya berkelanjutan.

\section{MATERI DAN METODE}

\section{Waktu dan Tempat Penelitian}

Penelitian dilaksanakan selama 4 bulan yaitu April hingga Juli 2015. Adapun Lokasi penelitian di Teluk Jailolo Kabupaten Halmahera Barat sedangkan pengolahan dan analisis citra dilakukan di Laboratorium Komputer Fakultas Perikanan dan IImu Kelautan.

\section{Prosedur Penelitian}

Kegiatan yang dilakukan dibagi ke dalam beberapa tahap, yaitu persiapan penelitian, pelaksanaan penelitian mencakup pengolahan data citra satelit, penentuan lokasi stasiun dan pengumpulan data populasi, pengambilan data parameter lingkungan, dan analisis data.

\section{Pengolahan Data Citra Satelit}

Metode yang dilakukan adalah metode Penginderaan Jauh (Remote Sensing), merupakan pengolahan data citra dari hasil perekaman sensor pada perangkat satelit ALOS AVNIR-2.

\section{Pengumpulan Data Ekologi Mangrove}

Adapun prosedur pengamatan dan pengambilan data mangrove yaitu: Menentukan jumlah stasiun, penempatan plot 50 × $50 \mathrm{~m}$ pada setiap stasiun dari pantai kearah darat dan mengidentifikasi dan menghitung 
jumlah anakan, mengukur diameter batang pohon mengrove menggunakan panduan Noor et al $(1999 ; 2012)$. Data kemudian diolah untuk memperoleh kerapatan spesies, frekuensi spesies, luas areal tutupan, nilai penting suatu spesies, frekuensi spesies, luas areal tutupan, nilai penting suatu spesies dan keanekaragaman spesies (Bengen, 2001)

\section{HASIL DAN PEMBAHASAN}

\section{Pengolahan Citra dan Analisis Citra}

Pengolahan dan analisis data citra ALOS AVNIR-22 meliputi import citra, koreksi geometrik, koreksi atmosferik, dan komposit citra yang prosesnya sebagai berikut :

\section{- Import Data Citra}

Import data citra dilakukan untuk menyesuaikan format data citra dengan software yang digunakan. Dalam penelitian ini citra yang digunakan ialah citra ALOS AVNIR2 yang tersimpan dalam format file *tiff, kemudian di import ke dalam format file *ers. agar dapat compatibel dengan software Er Mapper yang digunakan dalam penelitian. Citra yang digunakan merupakan citra ALOS AVNIR-2 dengan cakupan setiap scene perekaman mencakup $70 \times 70 \mathrm{~km}$, oleh sebab itu harus dilakukan pemotongan citra sesuai dengan lokasi penelitian yang melputi Teluk Jailolo (Gambar 1).

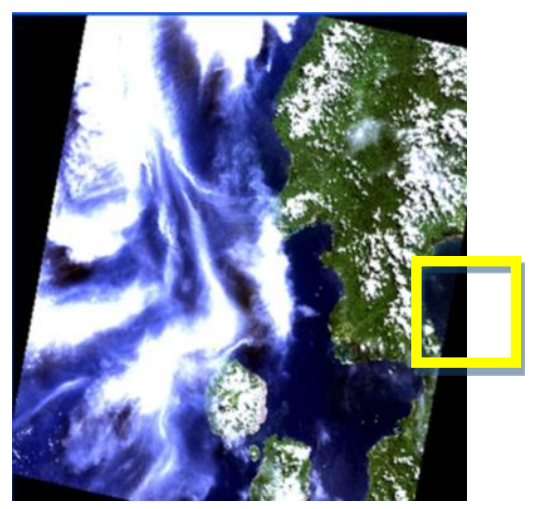

a

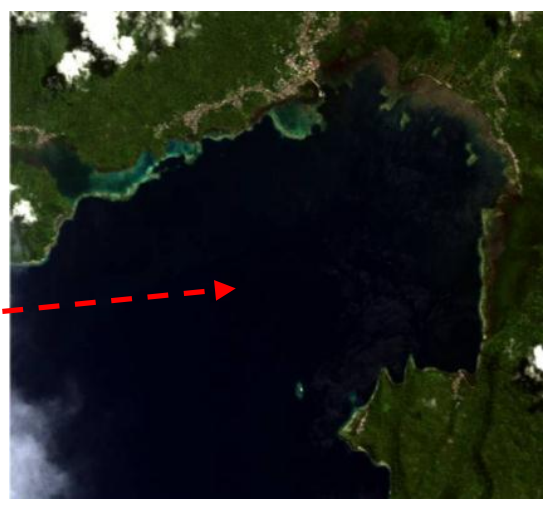

b

Gambar 1. (a) Sebelum Pemotongan (b) Hasil Pemotongan Citra ALOS AVNIR2

\section{- Koreksi Atmosferik}

Koreksi atmosferik dapat dilakukan dengan cara mencari nilai digital (DN) sebagai nilai pengoreksi (Dark Substrat). Metode koreksi atmosferik Dark Substrat yaitu menentukan nilai digital dari hasil kalkulasi statistic terhadap citra yang terdeteksi pada ditampilkan histogram citra 
digital. Gambaran visual Gambar 2 (khusus band 1) merupakan proses koreksi atmosferik cakupan citra Teluk Jailolo yang dilakukan dalam penelitian ini.

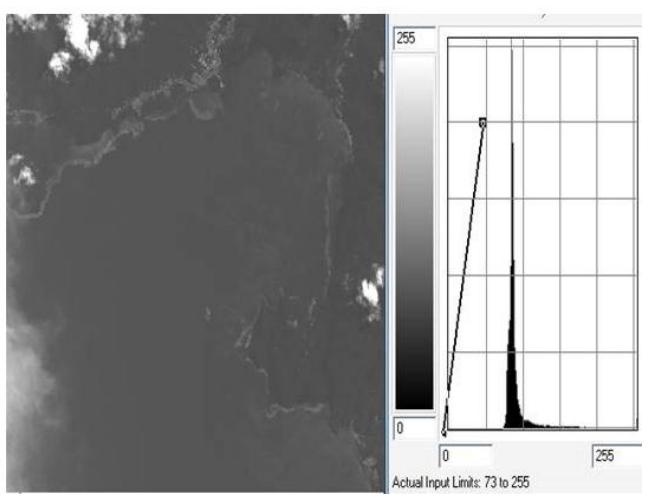

a

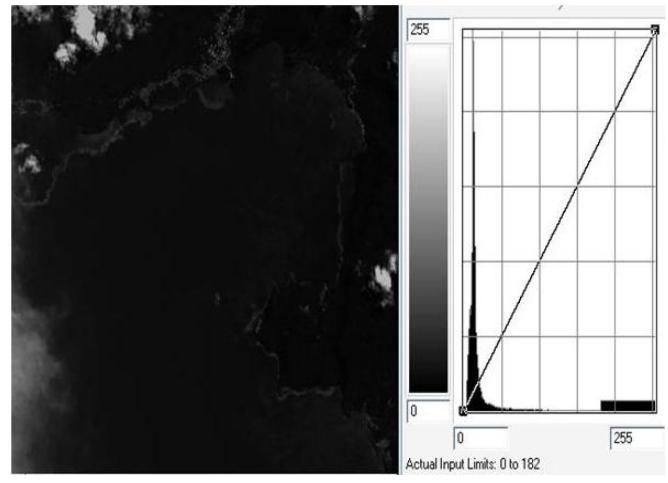

b

Gambar. 2. Koreksi Atmosferik Band 1 ALOS AVNIR-2 area Teluk Jailolo; (a) Citra sebelum Dikoreksi dan (b) Citra setelah Terkoreksi.

Hasil koreksi atmosferik band diketahui bahwa perbedaan antara citra sebelum dan sesudah koreksi atmosferik dapat dilihat pada model histogram dan nilai-nilai digital citra. Histogram dan nilai-nilai digital citra sebelum dilakukan koreksi atmosferik ditemukan nilai offset pada sumbu $x$ sedangkan pada citra yang telah terkoreksi atmosferik nilai tersebut sudah tidak ada. Secara matematis, melakukan koreksi atmosferik dibuat dengan melakukan pengurangan berdasarkan nilai offset pada sumbu $x$ terhadap semua nilai digital yang terdapat pada band citra (Tabel 1).

Tabel 1. Nilai Digital setiap Band yang Terkoreksi

\begin{tabular}{llll}
\hline Band & $\begin{array}{l}\text { Panjang Gelombang } \\
(\mu \mathrm{m})\end{array}$ & $\begin{array}{l}\text { Nilai Digital } \\
\text { setiap Band }\end{array}$ & $\begin{array}{l}\text { Nilal Digital setiap } \\
\text { Band } \\
\text { setelah terkoreksi }\end{array}$ \\
\hline 1 & Band 1 :0.42-0.50 & $73-255$ & $0-182$ \\
2 & Band 2 : 0.52 - 0.60 & $38-255$ & $0-217$ \\
3 & Band 3 : 0.61 - 0.69 & $19-255$ & $0-236$ \\
4 & Band 4 : 0.76-0.89 & $6-255$ & $0-249$ \\
\hline
\end{tabular}

\section{- Koreksi Geometrik}

Citra yang digunakan pada penelitian ini merupakan citra yang telah di koreksi geometrik terlebih dahulu sesuai dengan system koordinat bumi, agar semua informasi data citra sesuai keberadaannya di bumi (real 
word). Koreksi geometrik dalam penelitian ini menggunakan referensi proyeksi Universal Transverse Mercator (UTM) datum WGS84 dan Zone $52 \mathrm{~N}$. Ada dua istilah dalam koreksi geometrik, yaitu registrasi dan rektifikasi. Registrasi adalah proses koreksi geometrik dari citra belum terkoreksi dengan citra yang sudah terkoreksi. Rektifikasi adalah proses koreksi geometrik antara citra belum terkoreksi dengan peta. Dalam penelitian ini. Proses rektifikasi dilakukan terhadap citra ALOS AVNIR-2 dengan menggunakan peta Rupa Bumi Indonesia (RBI) 1:50.000.

Tabel 2. Koreksi Geometrik Citra ALOS AVNIR-2

\begin{tabular}{|c|c|c|c|c|c|c|}
\hline \multirow{2}{*}{ No } & \multicolumn{2}{|c|}{$\begin{array}{l}\text { Koordinat } \\
\text { Terkoreksi }\end{array}$} & \multicolumn{2}{|c|}{ Koordinat Pengoreksi } & \multirow{2}{*}{ RMS } & \multirow{2}{*}{$\begin{array}{l}\text { Keterangan } \\
\text { Referensi }\end{array}$} \\
\hline & $X$ & $Y$ & $X$ & $Y$ & & \\
\hline 1 & 6829.88 & 6601.13 & 344685,70 & $83.594,50$ & 0.04 & $\begin{array}{l}\text { Persimpangan } \\
\text { Jalan }\end{array}$ \\
\hline 2 & 4435.06 & 5860,25 & $320.753,43$ & 90.985 .95 & 0,34 & Belokan Jalan \\
\hline 3 & 5736,08 & 5131,76 & $333.780,24$ & $98.272,72$ & 0,69 & $\begin{array}{l}\text { Persimpangan } \\
\text { Jalan }\end{array}$ \\
\hline 4 & 7043,93 & 4110,17 & $346.860,17$ & $108.482,08$ & 0,31 & $\begin{array}{l}\text { Persimpangan } \\
\text { Jalan }\end{array}$ \\
\hline
\end{tabular}

\section{- Komposit Data Citra}

Pembuatan citra komposit dilakukan untuk memperoleh gambaran tentang jenis-jenis objek yang terdapat pada citra. Proses ini dilakukan dengan tujuan untuk memudahkan visualisasi dalam interpretasi pengenalan objek dan memudahkan dalam membuat klasifikasi objek pada citra. Proses komposit RGB dilakukan dengan membuat kombinasi warna dasar yang berbeda yaitu Merah (Red), Hijau (Green) dan Biru (Blue) yang terdapat pada pada tiga jenis saluran band pada citra tersebut. Contoh komposit yang dapat dibuat antara lain adalah komposit RGB 321 dan komposit RGB 432. Penelitian ini menggunakan Komposit RGB 432 karena jenis komposit ini lebih peka terhadap kandungan klorofil yang ditampilkan dengan warna semu (merah). Komposit RGB 432 dari citra ALOS AVNIR-2 terdapat pada Gambar 3. 

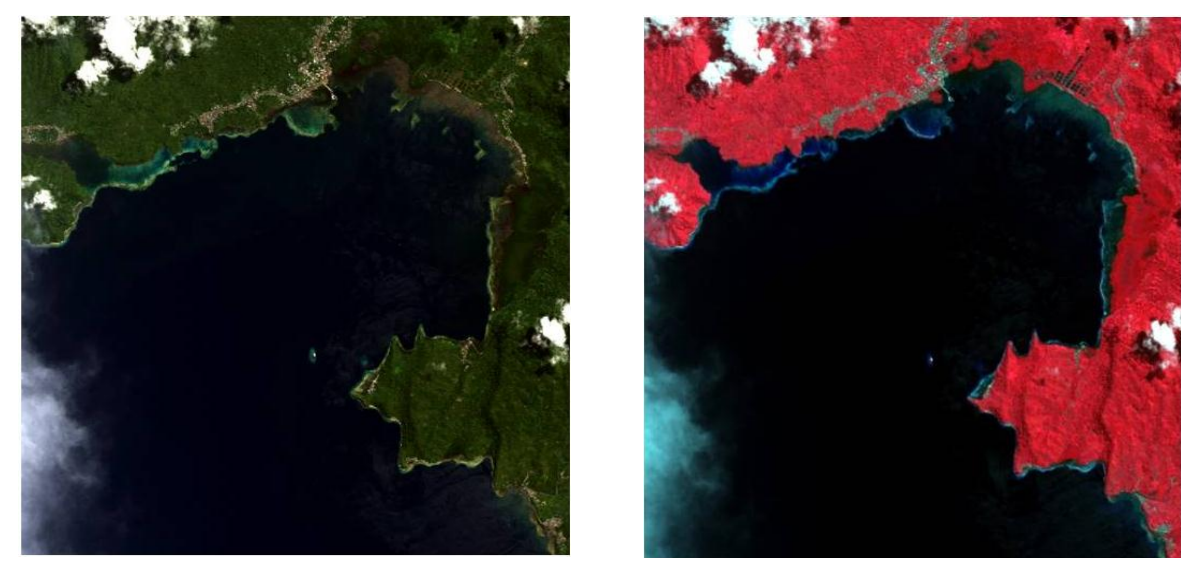

Gambar 3. Visualisasi Komposit citra ALOS AVNIR-2 yang digunakan dalam pemetaan; 432.

(a) citra 321 dan (b) komposit citra

\section{Interpretasi Citra}

Interpretasi citra ALOS AVNIR2 dengan visualisasi gelombang invisible melalui komposit RGB 432 (palse colour). Identifikasi objek pada data citra dilakukan melalui beberapa indikator seperti nilai digital pixel, warna, situs, dan rona. Adapun identifikasi objek melalui hasil interpretasi citra yang terkait dengan penelitian ini dapat di tentukan beberapa contoh objek seperti mangrove, vegetasi (hutan/semak belukar), permukiman, dan perairan (Tabel 3).

Tabel 3. Interpretasi Objek pada Citra Komposit 432

\begin{tabular}{llll}
\hline No $\quad$ Objek & Contoh visual & Deskripsi \\
\hline $1 \quad$ Mangrove & & $\begin{array}{l}\text { Terlihat dengan rona gelap } \\
\text { berwarna coklat sampai merah } \\
\text { tua dengan situs dekat dengan } \\
\text { garis pantai. }\end{array}$ \\
& & $\begin{array}{l}\text { Terlihat dengan rona cerah } \\
\text { hingga gelap dan warna merah, } \\
\text { tingkat kecerahan linier dengan } \\
\text { kelebatan vegetasi } \\
\end{array}$ Vegetasi & $\begin{array}{l}\text { Terlihat berwarna keabu-abuan } \\
\text { dengan rona cerah dengan } \\
\text { bentuk piksel yang teratur. }\end{array}$ \\
&
\end{tabular}




\begin{tabular}{ll}
\hline 4 Perairan & Terlihat dengan rona cerah \\
& hingga gelap, warna biru mudah \\
& sampai biru tua (hitam) bertekstur \\
halus
\end{tabular}

\section{Konversi Nilai Digital (DN) ke Nilai Radiansi dan Nilai Reflektansi}

Radiansi spectral adalah jumlah fluks energi per satuan luas, pada panjang gelombang tertentu. Dalam penelitian ini konversi nilai digital (DN) menjadi nilai radiansi dilakukan dengan menggunakan variabel yang terdapat pada Tabel 5.

Tabel 4. Radiansi Spektral Citra ALOS AVNIR-2

\begin{tabular}{llll}
\hline No & $\begin{array}{l}\text { Band } \\
(\boldsymbol{\mu m})\end{array}$ & $\begin{array}{l}\text { absCalCoef } \\
\left(\mathbf{W m}^{-2} \mathbf{s r}^{-1} \boldsymbol{\mu m}^{-1}\right)\end{array}$ & Offset \\
\hline 1 & $0.42-0.50$ & 0,5946 & 0,03 \\
2 & $0.52-0.60$ & 0,5541 & 0,02 \\
3 & $0.61-0.69$ & 0,4730 & 0,02 \\
4 & $0.76-0.89$ & 0,6689 & 0,00 \\
\hline
\end{tabular}

Hasil yang diperoleh dari konversi nilai digital ke nilai radiansi spectral tidak merubah tampilan visual data citra tetapi yang mengalami koreksi adalah nilai digital citra. Adapun nilai digital citra berdasarkan hasil konversi DN menjadi citra radiansi spectral dapat diketahui berdasarkan histogram citra masing-masing band (Gambar 4).
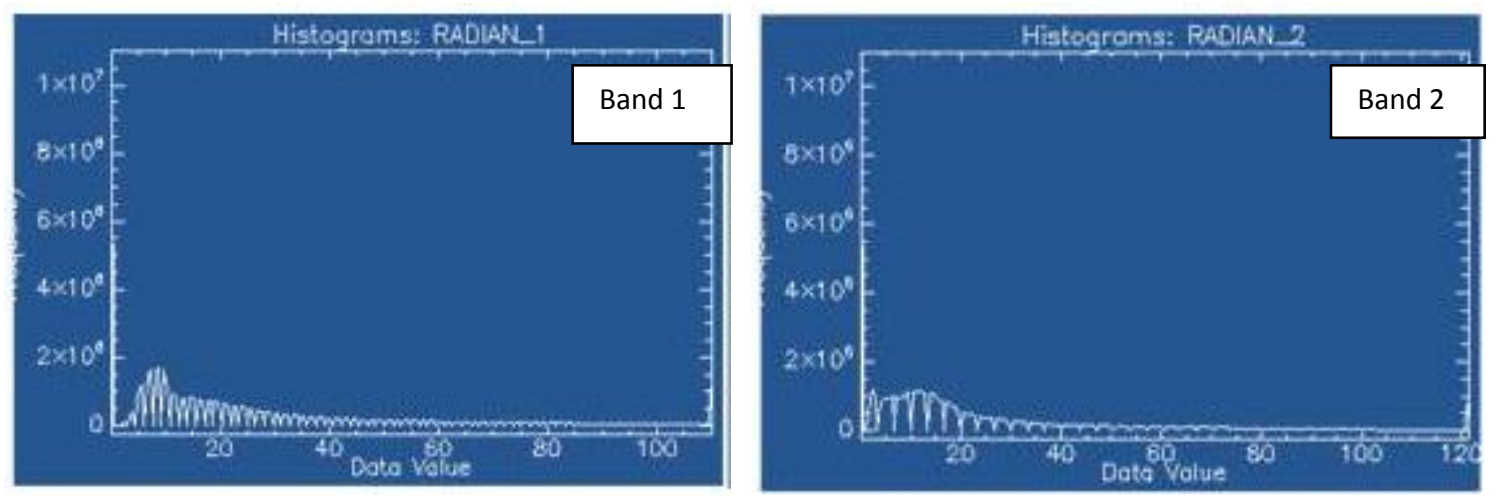
Jurnal Enggano Vol. 2, No. 2, September 2017: 143-155
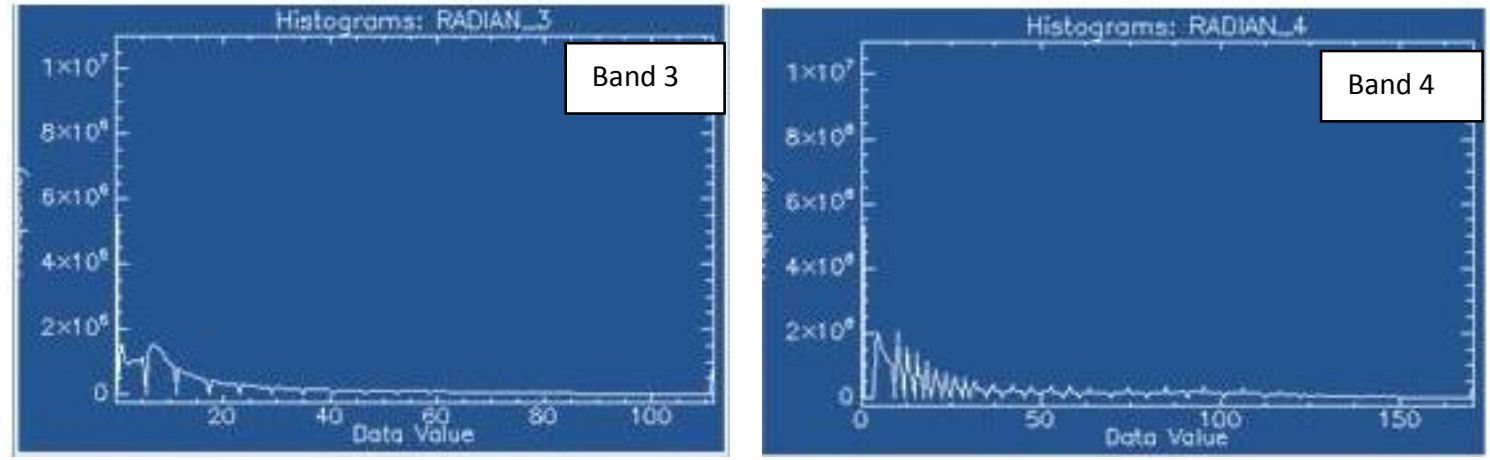

Gambar 4. Histogram Nilai Radiansi Spectral Citra ALOS AVNIR-2 di Teluk Jailolo (Radiansi Specktral Citra Band 1, 2, 3 dan 4)

\section{Hasil Analisis Algoritma Normalized Difference Vegetation Index (NDVI)}

\section{- Algoritma NDVI Mangrove Teluk Jailolo}

Analisis NDVI merupakan suatu algoritma yang dikembangkan dari penisbihan antara gelombang infra merah dan gelombang merah. Kelebihan dari algoritma ini adalah kemampuan dalam mengestimasi kandungan klorfil dengan kisaran nilai -1 sampai dengan 1. Semakin tinggi kandungan klorofil/kelebatan vegetasi maka nilai NDVI semakin mendekati nilai 1, dan sebaliknya. Oleh sebab itu, algoritma ini sangat sesuai dikembangkan dalam menentukan tutupan kanopi kerapatan klorofil/kanopi vegetasi. Adapun pemisahan vegetasi dengan mangrove dilakukan dengan analisis insert region. Analisis insert region merupakan teknik pemisahan objek pada citra berdasarkan jumlah region tertentu. Penentuan region dilakukan melalui proses delineasi citra. Dalam penelitian ini, analisis insert region terhadap mangrove berdasarkan hasil interpretasi pada komposit RGB 432 citra ALOS AVNIR-2 diketahui terdapat 10 jumlah region. Analisis algoritma melalui bahas logika if (inregion $r 1, r 2, r 3, r 4)$ then $b 1, b 2, b, \ldots b 10$ else null.

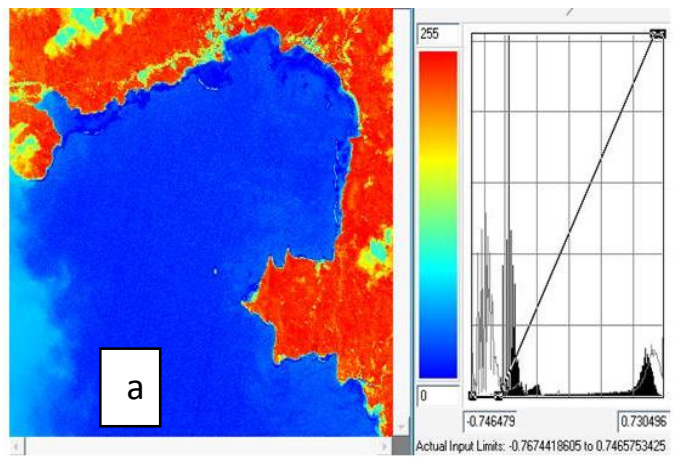

a

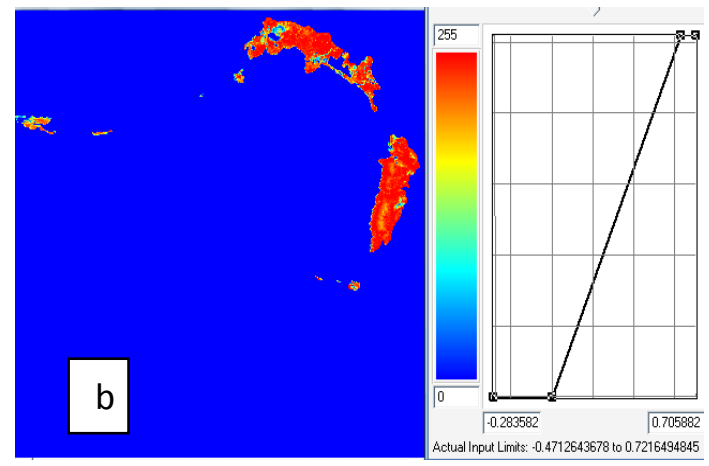

b

Gambar 5. Citra Hasil Aloritma NDVI Teluk Jailolo ; (a) NDVI Vegetasi (b) NDVI Mangrove 
Hasil analisis algoritma NDVI di Teluk Jailolo diketahui bahwa nilai NDVI vegetasi di wilayah ini berkisar antara -0.77 sampai dengan 0.75 (Gambar 5a). Adapun analisis NDVI (Gambar 5b)terhadap ekosistem mangrove yang terdapat di Teluk Jailolo diketahui bahwa nilai NDVI berkisar antara -0.47 sampai dengan 0.72. Berdasarkan Nilai NDVI mangrove tersebut maka dapat disimpulkan bahwa kondisi kerapatan mangrove di wilayah ini menyebar dalam kondisi kerapatan jarang hingga kerapatan lebat.

\section{- Sebaran Kerapatan Mangrove berdasarkan Algoritma NDVI}

Penentuan sebaran kerapatan mangrove di sekitar Teluk Jailolo dilakukan berdasarkan klasifikasi kisaran nilai NDVI yang mengacu pada modifikasi kisaran nilai NDVI yang telah ditetapkan oleh Dewanti et, al (1999) dalam menentukan nilai kerapatan kanopi. Klasifikasi tersebut menggolongkan kisaran nilai NDVI dengan kriteria kerapatan sebagai berikut (a) kerapatan sangat jarang jika nilai NDVI $<=0.18$, (b) jarang jika nilai NDVI 0.18 sampai 0.32 , (c) sedang jika nilai NDVI 0.32 sampai 0.42 , dan (d) lebat jika nilai NDVI $>=0.42$.

Hasil analisis algoritma NDVI diketahui bahwa nilai NDVI mangrove yang terdapat di Teluk Jailolo berkisar antara -0.47 sampai dengan 0.72 . Berdasarkan kisaran nilai NDVI tersebut diketahui bahwa sebaran kerapatan mangrove di wilayah ini meliputi mangrove kerapatan sangat jarang, mangrove kerapatan jarang, mangrove kerapatan sedang, dan mangrove kerapatan lebat (Gambar 6).

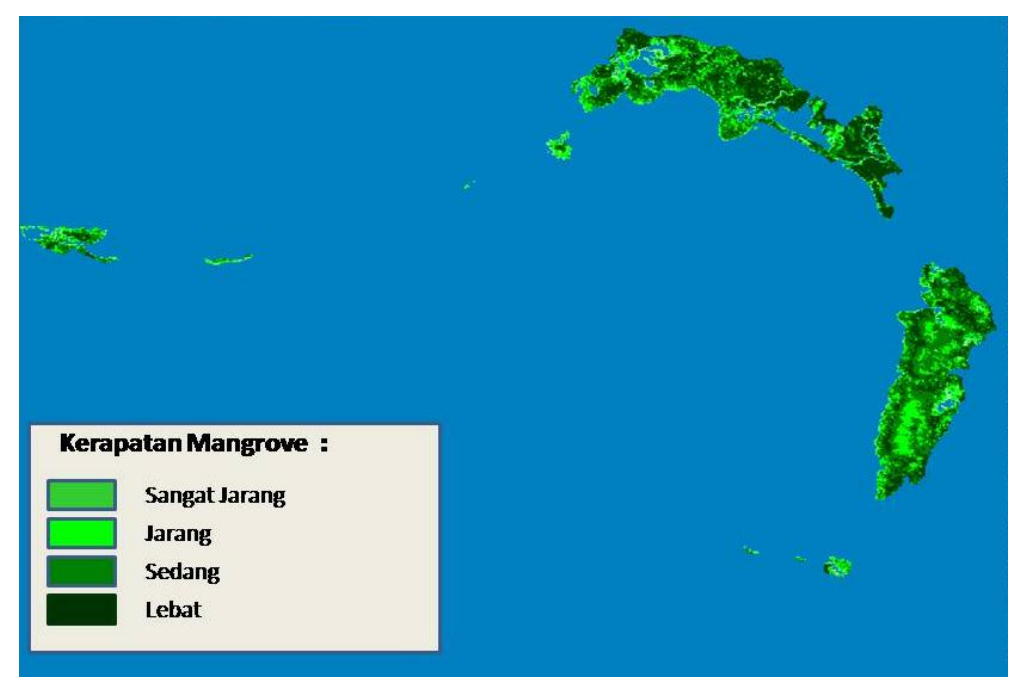

Gambar 6. Peta Sebaran Kerapatan Mangrove di Teluk Jailolo berdasarkan Klasifikasi Nilai NDVI

Eksistensi sebaran populasi hutan mangrove di sekitar Teluk Jailolo berdasarkan analisis citra Alos Avnir-2 diketahui berjumlah 393.77 ha di daerah garis pantai dengan pola penyebaran sebagian besar terletak di 
pantai sisi bagian timur Teluk Jailolo. Kondisi sebaran kerapatan hutan mangrove di Teluk Jailolo berdasarkan nilai NDVI (Tabel 5).

Tabel 5. Sebaran Kerapatan Mangrove di sekitar Teluk Jailolo

\begin{tabular}{llll}
\hline No & Kategori Kerapatan & \multicolumn{2}{c}{ Luas Mangrove Teluk jailolo } \\
\cline { 3 - 4 } & Kanopi & Hektar $(\mathrm{Ha})$ & Persen $(\%)$ \\
\hline 1 & Sangat Jarang & 20.18 & 5.12 \\
2 & Jarang & 91.97 & 23.36 \\
3 & Sedang & 157.83 & 40.08 \\
4 & Lebat & 123.79 & 31.44 \\
\hline & Jumlah & 393.77 & 100 \\
\hline
\end{tabular}

Penentuan sebaran kerapatan hutan mangrove disekitar Teluk Jailolo dilakukan berdasarkan hasil klasifikasi citra berdasarkan nilai NDVI. Untuk mengetahui ketelitian terhadap hasil klasifikasi citra maka perlu dilakukan uji ketelitian melalui uji kebenaran lapangan. Hasil ketelitian klasifikasi citra yang digunakan dalam penelitian ini berdasarkan uji kebenaran lapangan (ground truth) (Tabel 6).

Tabel 6. Hasil Uji Lapangan (Ground truth) dengan Data Citra

\begin{tabular}{|c|c|c|c|c|c|c|c|c|}
\hline Lapangan/ Citra & Ml & Ms & $\mathrm{Mj}$ & Msj & NM & Benar & Salah & Total \\
\hline $\begin{array}{ll}\text { Mangrove } & \text { lebat } \\
(\mathrm{MI}) & \end{array}$ & 6 & - & - & - & - & 6 & - & 6 \\
\hline $\begin{array}{l}\text { Mangrove sedang } \\
\text { (Ms) }\end{array}$ & 1 & 5 & - & - & - & 5 & 1 & 6 \\
\hline $\begin{array}{l}\text { Mangrove jarang } \\
(\mathrm{Mj})\end{array}$ & - & 1 & 4 & 1 & - & 4 & 2 & 6 \\
\hline $\begin{array}{l}\text { Mangrove sangat } \\
\text { jarang (Msj) }\end{array}$ & - & - & - & 5 & 1 & 5 & 1 & 6 \\
\hline $\begin{array}{l}\text { Non } \quad \text { Mangrove } \\
\text { (NM) }\end{array}$ & - & - & - & - & 6 & 6 & - & 6 \\
\hline & \multicolumn{5}{|c|}{ Total } & 26 & 4 & 30 \\
\hline & \multicolumn{5}{|c|}{ Persen Salah \% } & & 13.33 & - \\
\hline & & \multicolumn{4}{|c|}{ Persen benar $\%$} & 86.67 & & - \\
\hline
\end{tabular}

Hasil uji kebenaran lapangan sebaran kerapatan mangrove berdasarkan nilai NDVI dengan mengelompokkan (cluster) objek penelitian diperoleh dengan nilai presentase kebenaran 86,67\% dan presentase kesalahan 13,33\%. Uji ketelitian yang dilakukan terhadap hasil klasifikasi nilai NDVI tersebut berdasarkan fakta lapangan secara 
keseluruhan diperoleh ketelitian yang akurat, karena nilai kebenaran lebih besar dari 85 \% (Nurlidiasari, 2004, 2005 ; Siregar, 2008).

\section{KESIMPULAN DAN SARAN}

Kesimpulan yang dapat diperoleh dari hasil penelitian yaitu luas mangrove yang terdapat di Teluk Jailolo adalah 393.77 ha dengan kategori tingkat kerapatan sangat jarang hingga lebat. Berdasarkan analisis NDVI diketahui bahwa luas mangrove untuk kategori sangat jarang 20.18 ha, jarang 91.97 ha, sedang 157.83 ha, dan lebat 123.79 ha. Adapun saran yang direkomendasikan adalah perlu dilakukan penelitian lanjutan tentang model dan pengelolaan ekosistem hutan mangrove

\section{UCAPAN TERIMA KASIH}

Penulis mengucapkan terima kasih kepada Kementrian Riset dan Teknologi Pendidikan Tinggi atas dana hibah yang diberikan untuk penelitian ini. Selain itu juga kepada Dinas Kelautan dan Perikanan serta masyarakat yang membantu penulis selama pengambilan data dilapangan.

\section{DAFTAR PUSTAKA}

Aziz A. 2003. Kajian Pengembangan Pariwisata Bahari di Kelurahan Pulau Kelapa Kecamatan Kepulauan Seribu Utara, Kabupaten Administrasi Kepulauan Seribu, Daerah Khusus Ibukota Jakarta. Tesis. Bogor: Program Pascasarjana Institut Pertanian Bogor.

Bengen, D.G. 2001. Pedoman Teknis Pengenalan dan Pengelolaan Ekosistem Mangrove. Pusat Kajian Sumberdaya Pesisir dan Lautan - Institut Pertanian Bogor. Bogor, Indonesia.

Dahuri, Rokhmin, J. Rais, S.P. Ginting, \& M.J. Sitepu. 2001. Pengelolaan Sumberdaya Wilayah Pesisir dan Lautan Secara Terpadu. Pradnya Paramitha. Jakarta.

Dewanti, R, T. Maulana, S. Budiman, F. Zinuddin \& Munyati. 1999. Kondisi Hutan Mangrove di Kalimantan Timur, Sumatera, Jawa, Bali, dan Maluku. Majalah LAPAN, Edisi Penginderaan Jauh, (91) : 2943.

Noor, Y.R., M. Khazali, M. \& I.N.N Suryadiputra. 1999. Panduan Pengenalan Mangrove di Indonesia. PKA/ WI-IP, Bogor 
Noor, Y. R, M. Khazali, \& I.N.N Suryadiputra. 2012. Panduan pengenalan mangrove di Indonesia. Cetakan ke-3. Bogor: Wetlands International Indonesia Programme

Nurlidiasari, M. 2004. The Application of QuickBird and Multi-temporal Landsat TM Data for Coral Reef Habitat Mapping Case Study: Derawan Island, East Kalimantan, Indonesia. MSc Thesis. International Institute for Geo-Information Science and Earth Observation - ITC, Enschede, the Netherlands.

Nurlidiasari, M \& SA Budiman. 2005. Mapping Coral Reef Habitat With and Without Water Column Correction Using Quickbird Image. Remote Sensing And Earth Sciences. September 2005. Vol 2 : 45- 56.

Siregar,V. P. 2008. Pendugaan Potensi Ikan Karang Dengan Citra Satelit Resolusi Tinggi dan Merancang Alat Tangkap yang Sekektif di Kepulauan Seribu.Bogor: SEAMEO BIOTROP 